\title{
Erratum to: Inflammation, glucose, and vascular cell damage: the role of the pentose phosphate pathway
}

Concepción Peiró ${ }^{1}$, Tania Romacho 1,4 ${ }^{\text {, Verónica Azcutia1, }}{ }^{1,5}$, Laura Villalobos ${ }^{1}$, Emilio Fernández², Juan P. Bolaños², Salvador Moncada ${ }^{3,6^{*}+}$ and Carlos F. Sánchez-Ferrer ${ }^{1^{*} \dagger}$

\section{Erratum to: Cardiovasc Diabetol (2016) 15:82 DOI 10.1186/s12933-016-0397-2}

After publication of the original article [1], it became apparent that an error affecting Fig. 6 occurred during production. In the published article, Fig. $6 a$ is missing the Western blot corresponding to G6PD.
The correct version of the figure was submitted by the author, and the error occurred during the typesetting stage. The correct version (Fig. 6) of the figure is published in this erratum.

\footnotetext{
*Correspondence: salvador.moncada@manchester.ac.uk; carlosf.sanchezferrer@uam.es

${ }^{\dagger}$ Carlos F. Sánchez-Ferrer and Salvador Moncada jointly directed this work

1 Departamento de Farmacología, Facultad de Medicina, Universidad Autónoma de Madrid, 29029 Madrid, Spain

${ }^{6}$ Present Address: Institute of Cancer Sciences, Manchester

Cancer Research Centre, University of Manchester, Wilmslow Road,

Manchester M20 4QL, UK

Full list of author information is available at the end of the article
} 


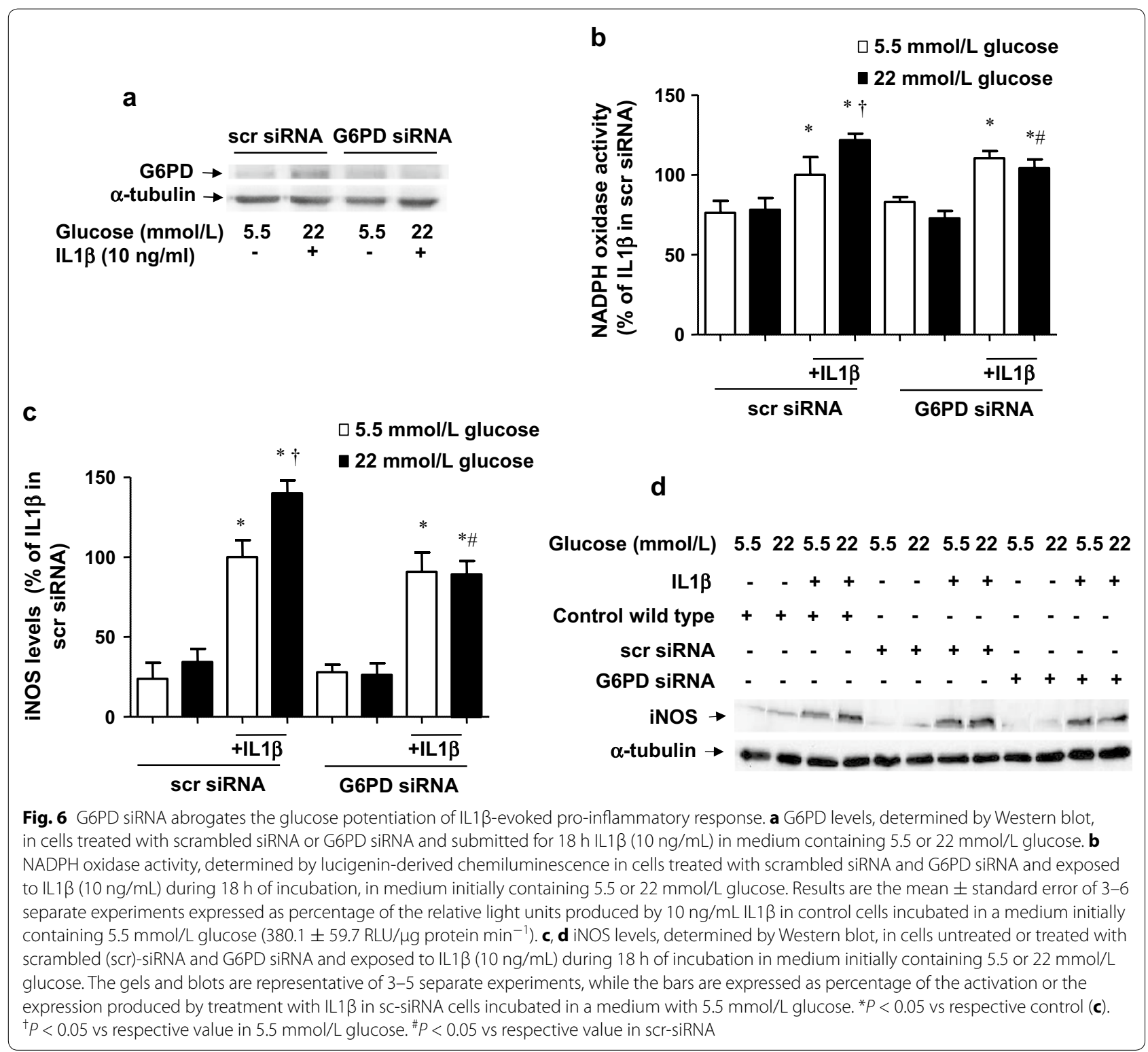

\section{Author details}

${ }^{1}$ Departamento de Farmacología, Facultad de Medicina, Universidad Autónoma de Madrid, 29029 Madrid, Spain. ${ }^{2}$ Instituto de Biología Funcional y Genómica, Universidad de Salamanca-CSIC, 37007 Salamanca, Spain. ${ }^{3}$ Wolfson Institute for Biomedical Research, University College London, London WC1E 6BT, UK. ${ }^{4}$ Present Address: Paul Langerhans-Group, Integrative Physiology, German Diabetes Center, Auf'm Hennekamp 65, 40225 Düsseldorf, Germany. ${ }^{5}$ Present Address: Department of Pathology, University of Michigan, Ann Arbor, MI 48109, USA. ${ }^{6}$ Present Address: Institute of Cancer Sciences, Manchester Cancer Research Centre, University of Manchester, Wilmslow Road, Manchester M20 4QL, UK.

The online version of the original article can be found under doi:10.1186/s12933-016-0397-2.

\section{Reference}

1. Peiró C, Romacho T, Azcutia V, Villalobos L, Fernández E, Bolaños JP, MoncadaS, Sánchez-Ferrer CF. Inflammation, glucose, and vascular cell damage: the role of the pentose phosphate pathway. Cardiovasc Diabetol. 2016;15:82. doi:10.1186/s12933-016-0397-2. 